\title{
PELATIHAN DALAM MENETAPKAN STRATEGI KOMUNIKASI PEMASARAN YANG TEPAT UNTUK PRODUK DAN JASA DARI UKM
}

\author{
${ }^{1}$ Luki Adiati Pratomo, ${ }^{2}$ Lavlimatria Esya, ${ }^{3}$ Ayu Ekasari, ${ }^{4}$ Ulfi Naria Rahmawati, \\ ${ }^{5}$ Wanggi Citra Ameliana \\ 1Program Studi S1 Manajemen, Universitas Trisakti, Jakarta, Indobesia \\ 2Program Studi S1 Ilmu Ekonomi, Universitas Trisakti, Jakarta, Indonesia \\ ${ }^{3}$ Program Studi S3 Ilmu Ekonomi, Universitas Trisakti, Jakarta, Indonesia \\ 4Program Studi Manajemen, Universitas Trisakti, Jakarta, Indonesia \\ ${ }^{5}$ Program Studi S1 Manajemen, Universitas Trisakti, Jakarta, Indonesia \\ E-mail: luki.adiati@trisakti.ac.id
}

(Diterima: 22 September 2021; Direvisi: 10 Oktober 2021; Dipublikasikan: November 2021)

\begin{abstract}
ABSTRAK
Pandemi COVID-19 menyebabkan kesulitan bagi pengusaha kecil dan menengah, termasuk para mahasiswa Sekolah Kewirausahaan Bina Amanah Cordova yang merupakan sekolah diploma 1 (D1) yang gratis. Peserta didik atau mahasiswa SKBAC kebanyakan merupakan wirausaha muda atau calon wirausaha yang saat ini mengalami kesulitan seperti penjualan yang menurun bahkan terpaksa tutup akibat COVID-19. Salah satu penyebab turunnya penjualan adalah kesulitan berkomunikasi dengan konsumennya mengingat masyarakat memilih tidak keluar rumah untuk belanja. Untuk itu dilakukan pelatihan mengenai strategi komunikasi pemasaran agar mereka dapat mengembangkan strategi komunikasi pemasaran yang efektif dalam menjangkau konsumen sasarannya. Metode dalam melaksanakan kegiatan pelatihan adalah memberikan penyuluhan kepada para mahasiswa. Para penyuluh menjelaskan beberapa alat yang dapat digunakan dalam komunikasi pemasaran seperti periklanan, promosi penjualan, acara dan pengalaman, pemasaran langsung, publikasi, pemasaran social media, dan penjualan perseorangan. Hasil dari pelatihan ini, terlihat bahwa peserta didik mulai memhami pentingnya komunikasi pemasaran, dapat mengembangkan strategi komunikasi pemasaran yang tepat dan dapat memilih alat komunikasi yang tepat, salah satunya adalah pemasaran social media.
\end{abstract}

Kata Kunci: Covid-19 Komunikasi Pemasaran, Bauran Promosi, Penyuluhan

\section{ABSTRACT:}

The COVID-19 pandemic has caused difficulties for small and medium-sized entrepreneurs, including students of the Bina Amanah Cordova School of Entrepreneurship which is a freediploma 1 (D1) school. SKBAC students or students are mostly young entrepreneurs or prospective entrepreneurs who are currently experiencing difficulties such as declining sales and even being forced to close due to COVID19. One of the causes of the decline in sales is the difficulty of communicating with consumers considering that people choose not to leave their homes for shopping. For this reason, training on marketing communication strategies is carried out so that they can develop effective marketing communication strategies in reaching their target consumers. The method in carrying out training activities is to provide counseling to students. The counselors explain some of the tools that can be used in marketing communications such as advertising, sales promotion, events and experiences, direct marketing, publications, social media marketing, and personal selling. The results of this training show that students begin to understand the importance of marketing communication, can develop appropriate marketing communication strategies and can choose the right communication tools, one of which is social media marketing.

Keywords: Covid-19, Marketing Communication, Promotion Mix, Extension. 


\section{PENDAHULUAN}

Pandemi COVID-19 telah menyebabkan timbulnya banyak masalah bagi masyarakat, termasuk diantaranya usaha kecil dan menengah (ARIANTO, 2020). Banyak sekali UMKM mengalami penurunan penjualan, bahkan banyak diantaranya terpaksa tutup dan gulung tikar (Nasution et al., 2020). Hal itu tentu saja menyebabkan peningkatan pengangguran dan akhirnya kemiskinan di Indonesia semakin parah (Indayani \& Hartono, 2020)

Sekolah Kewirausahaan Bina Amanah Cordova merupakan sekolah yang memberikan Pendidikan mengenai kewirausahaan pada level Diploma Satu. Mahasiswa tidak perlu membayar di Cordova, sesuai dengan tujuan sekolah untuk membantu mengembangkan kemampuan berwirausaha bagi anak muda dan pengusaha kecil. Pandemi COVID-19 ini menyebabkan semakin banyaknya mahasiswa di Sekolah Kewirausahaan Bina Amanah Cordova karena banyaknya orang yang kehilangan pekerjaan. Para pengusaha kecil, muda maupun tua yang mengalami kesulitan dalam masa pandemic ini kemudian mengikuti kuliah di Cordova untukmencari pengetahuan dan peluang usaha. Hal ini juga menyebabkan timbulnya masalah karena jumlah mahasiswa yang menjadi lebih banyak dibandingkan kapasitas sekolah.

Berkomunikasi dengan konsumen merupakan salah satu masalah yang dihadapi oleh pelaku UMKM. Kebanyakan dari mereka belum memahami cara menyampaikan informasi dan berkomunikasi yang efektif dengan calon konsumen, sementara pandemic COVID-19 ini menyebabkan perubahan perilaku konsumen, salah satunya enggan keluar rumah (Yuswohady, et al, 2020).

Mencermati masalah yang timbul di masyarakat dan juga pada Sekolah Kewirausahaan Bina Amanah Cordova (SKBAC), maka tim PKM dari Fakultas Ekonomi dan Bisnis Universitas Trisakti mengadakan lebih banyak pelatihan bagi mahasiswa SKBAC. Salah satu pelatihan yang diperlukan, mengingat kesulitan pengusaha UMKM untuk berkomunikasi dengan konsumen, maka dikembangkanlah pelatihan mengenai strategi komunikasi pemasaran dengan konsumen. Pemanfaatkan media online berbasis website pun dapat digunakan sebagai fasilitas dalam penjualan atau promosi produk kepada konsumen (Haryadi et al., 2021). Tujuan pelatihan ini adalah memperkenalkan dan memberikan gambaran mengenai berbagai strategi komunikasi pemasaran yang dapat digunakan untuk mempromosikan produk atau jasa para pengusaha UMKM. Diharapkan dengan pemahaman tersebut, para anak didik di SKBAC akan dapat mengembangkan strategi pemasaran yang tepat dan efektif.

\section{METODE}

Metode yang digunakan dalam melaksanakan pelatihan strategi komunikasi pemasaran pada para peserta didik di SKBAC adalah tehnik penyuluhan. Penyuluhan merupakan suatu cara untuk memberikan tambahan pengetahuan dan kemampuan seseorang melalui tehnik berupa praktek belajar dengan tujuan mengubah perilaku manusia secara individu maupun 166 
perorangan (Amini et al., 2018). Tehnik penyuluhan yang dimaksud dalam pelaksanaan pelatihan disini merupakan proses pembelajaran bagi peserta didik yang juga pengusaha kecil dan mikro, agar dapat mengenali berbagai macam alat dalam melakukan komunikasi pemasaran sehingga mereka dapat memilih alat yang paling tepat dalam memasarkan produkatau jasanya.

Pelatihan dilaksanakan pada hari Sabtu tanggal 20 Maret 2021 di Sekolah Kewirausahaan Bina Amanah Cordova secara daring, mengingat kondisi masih pandemi sehingga sangat tidak disarankan untuk bertemu secara langsung.

Tahapan yang dilakukan dalam menyiapkan dan kemudian melaksanakan pelatihan terdiri dari :

\begin{tabular}{|c|c|c|c|}
\hline N0 & Kegiata & Tahapan Kegiatan & Target Kegiatan \\
\hline 1 & $\begin{array}{l}\text { Membuat } \\
\text { database } \\
\text { Mahasiswa } \\
\text { SKBAC }\end{array}$ & $\begin{array}{l}\text { Melakukan pengumpulan data } \\
\text { mengenai kondisi mahasiswa } \\
\text { Sekolah Kewirausahaan Bina } \\
\text { Amanah Cordova }\end{array}$ & $\begin{array}{l}\text { Dapat memastikan: } \\
\text { 1. Jumlah dan nama-nama } \\
\text { mahasiswa yang belum } \\
\text { memiliki usaha } \\
\text { 2. Jumlah dan nama-nama } \\
\text { mahasiswa yang sudah } \\
\text { memiliki usaha } \\
\text { 3. Mengetahui jenis usaha } \\
\text { mereka dan mereknya bila } \\
\text { sudah ada }\end{array}$ \\
\hline 2 & Pelatihan & $\begin{array}{l}\text { Melaksanakan pelatihan dalam } \\
\text { bentuk penyuluhan mengenai } \\
\text { komunikasi pemasaran }\end{array}$ & $\begin{array}{l}\text { Peserta mengenal dan } \\
\text { memahami beberapa jenis alat } \\
\text { komunikasi pemasaran }\end{array}$ \\
\hline 3 & $\begin{array}{l}\text { Pembuatan } \\
\text { strategi }\end{array}$ & $\begin{array}{l}\text { Melakukan pengembangan alat } \\
\text { komunikasi pemasaran }\end{array}$ & $\begin{array}{l}\text { Peserta membuat rencana } \\
\text { penggunaan alat komunikasi } \\
\text { pemasaran sesuai produk } \\
\text { atau jasanya }\end{array}$ \\
\hline 4 & $\begin{array}{l}\text { Pembuatan } \\
\text { salah satu } \\
\text { alat }\end{array}$ & $\begin{array}{l}\text { Membantu membuat salah satu } \\
\text { alat komunikasi pemasaran }\end{array}$ & $\begin{array}{l}\text { Peserta membuat contoh salah } \\
\text { satu alat komunikasi } \\
\text { pemasaran }\end{array}$ \\
\hline
\end{tabular}

\section{HASIL DAN PEMBAHASAN}

Pelatihan dilaksanakan pada hari Sabtu 20 Maret 2021, menggunakan metode penyuluhan secara daring, dengan zoom meeting. Peserta didik yang hadir berjumlah 29 siswa yang terdiri dari 19 wanita dan 10 pria. Menarik sekali ternyata kebanyakan peserta merupakan pengusaha kecil yang bergerak dibidang makanan, hanya sedikit sekali yang bergerak di bidang fashion dan kecantikan. Hal ini sesuai dengan kondisi pandemi, kebanyakan konsumen tidak berbelanja kebutuhan sekunder seperti baju dan kosmetik. Umumnya konsumen lebih 
berkonsentrasi untuk berbelanja makanan yang merupakan kebutuhan primer.

Bila dilihat dari status pernikahan, ternyata lebih dari 50\% sudah menikah, bahkan usia terbanyak sekitar 40 tahun, walaupun Pendidikan mereka rata-rata lulus SMA. Hal ini menunjukkan bahwa para pengusaha UMKM, walaupun sudah berusia cukup matang tetap ingin menambah pengetahuan.

Pelatihan ini menjelaskan konsep-konsep penting dari komunikasi pemasaran, alat- alat komunikasi pemasaran yang dapat digunakan serta bagaimana memilih alat yang sesuai (Kotler \& Keller, 2011). Beberapa alat komunikasi pemasaran yang penting adalah periklanan, promosi penjualan, acara dan pengalaman, pemasaran melalui social media, mobile marketing, pemasaran secara langsung dan penjualan perseorangan (Kotler \& Keller, 2011).

Tentu saja tidak semua alat berguna bagi usaha kecil dan menengah, untuk itu perlu pemahaman mengenai karakteristik, kekuatan dan kelemahan dari masing-masing alat tersebut. Misalnya para peserta perlu memahami kekuatan dan kelemahan iklan (Jiang \& Wei, 2012), promosi penjualan (Human et al., 2018), word of mouth (Hidayanto et al., 2017), penjualan perorangan (Liu \& Comer, 2007) dan pengalaman sebagai cara menyampaikan komunikasi pemasaran (Gallarza, Arteaga, Del Chiappa, \& Gil-Saura, 2015; Pratomo \& Magetsari, 2018).

Sebagai pengusaha UMKM memang sangat perlu menerapkan komunikasi pemasaran yang tepat agar konsumen mengenali produk dan jasa mereka. Salah satu cara yang saat ini sangat populer dan mudah digunakan adalah e-commerce dan social media (Awali, 2020).

Tabel 1

Evaluasi Peserta Didik mengenai Materi Komunikasi Pemasaran

\begin{tabular}{|c|l|r|l|l|}
\hline No & \multicolumn{1}{|c|}{ Keterangan } & Jumlah & Rata-rata & SD \\
\hline 1 & $\begin{array}{l}\text { Saya memahami pengertian komunikasi } \\
\text { pemasaran dengan baik }\end{array}$ & 29 & 4.3448 & .66953 \\
\hline 2 & Saya memahami tujuan komunikasi pemasaran & 29 & 4.5862 & .56803 \\
\hline 3 & $\begin{array}{l}\text { Saya mengerti alat-alat yang bisa digunakan } \\
\text { untuk melakukan komunikasi pemasaran }\end{array}$ & 29 & 4.3103 & .76080 \\
\hline 4 & Saya memahami konsep tentang digital marketing & 29 & 4.0000 & .84515 \\
\hline 5 & $\begin{array}{l}\text { Saya bisa menerapkan Konsep digital marketing } \\
\text { dalam bisnis/ rencana bisnis saya }\end{array}$ & 29 & 3.9310 & .88362 \\
\hline
\end{tabular}

Sumber : Pengolahan data menggunakan SPSS

Berdasarkan survey yang dilakukan kepada para peserta didik mengenai materi Komunikasi Pemasaran yang terlihat dalam tabel 1 , setelah mengikuti pelatihan, mereka menjadi lebih memahami komunikasi pemasaran, beberapa tujuan komunikasi pemasaran dan berbagai alat yang dapat digunakan dalam berkomunikasi dengan konsumen. Selain itu, para peserta didik juga menjadi lebih paham mengenai konsep digital marketing dan bagaimana menerapkan digital marketing dalam rencana bisnis mereka. 
Tabel 2

Hasil Evaluasi Peserta Didik Mengenai Pelatihan

\begin{tabular}{|c|l|l|l|l|}
\hline No & \multicolumn{1}{|c|}{ Keterangan } & Jumlah & Rata- rata & SD \\
\hline 1 & $\begin{array}{l}\text { Pendapat peserta didik tentang kesesuaian PKM } \\
\text { terhadap manfaat yang bapak/ibu peroleh }\end{array}$ & 29 & 4.6552 & .48373 \\
\hline 2 & Materi yang disajikan menarik & 29 & 4.5172 & .63362 \\
\hline 3 & Instruktur mengusai materi pelatihan & 29 & 4.4483 & .63168 \\
\hline 4 & Mampu menjelaskan materi dengan baik & 29 & 4.6207 & .49380 \\
\hline 5 & Materi Pelatihan Sesuai Dengan Kebutuhan Anda & 29 & 4.5517 & .63168 \\
\hline 6 & $\begin{array}{l}\text { Materi Yang Diberikan Lengkap Dan Dapat } 29 \\
\text { Dengan }\end{array}$ & 4.4483 & .68589 \\
\hline
\end{tabular}

Sumber : Pengolahan data menggunakan SPSS

Sedangkan berdasarkan tabel 2 , terlihat bahwa peserta didik beranggapan bahwa pelatihan yang diberikan sesuai dengan harapan mereka, materi yang disajikan lengkap dan menarik, para instruktur memang menguasai materi dan dapat menjelaskan dengan baik.

Gambar 1 dan 2 :

Pelaksanaan pelatihan Komunikasi Pemasaran di SKBAC secara daring

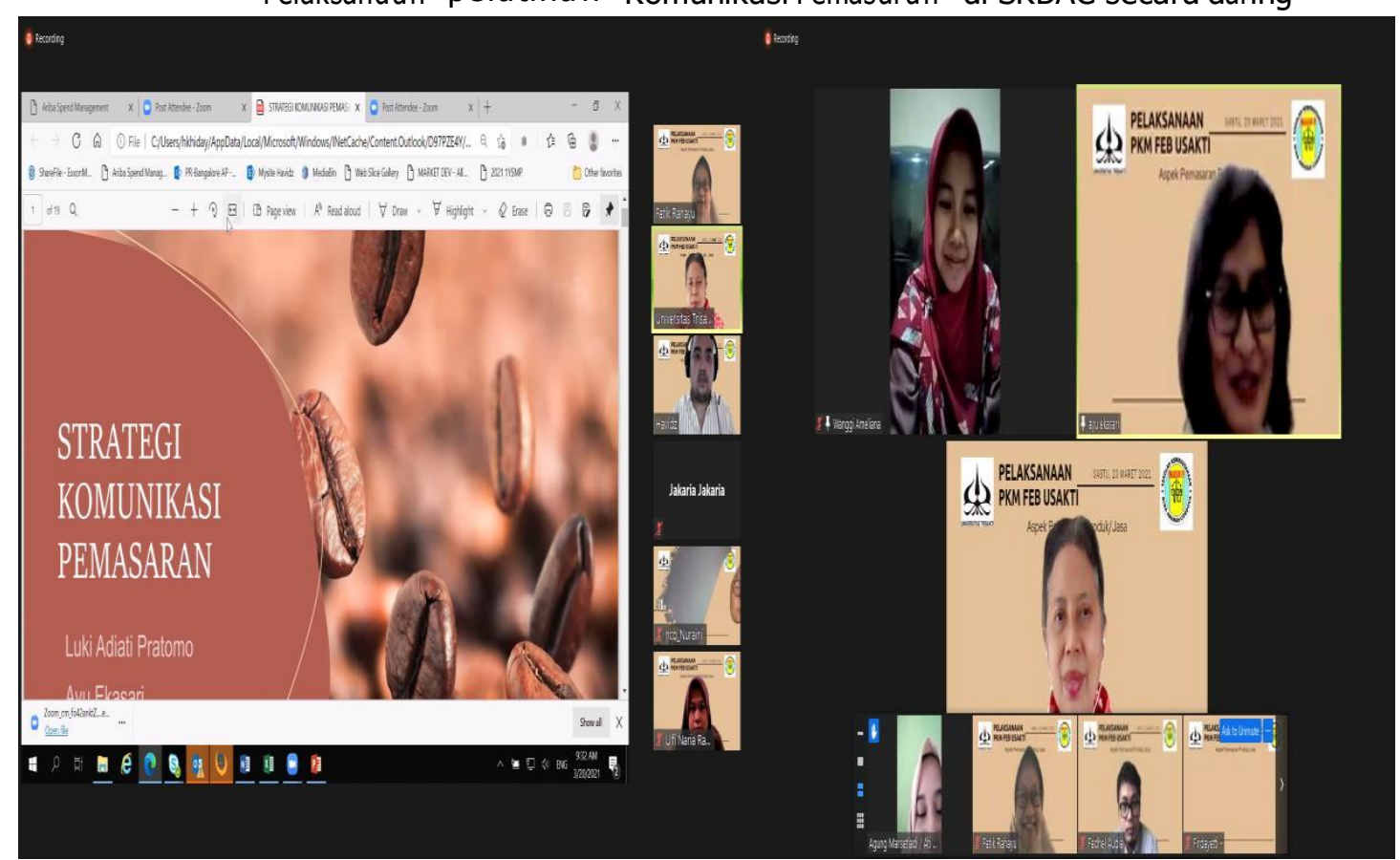

Kedua gambar diatas memperlihatkan proses pelatihan yang dilaksanakan pada hari Sabtu tanggal 21 Maret 2021 di Sekolah Kewirausahaan Bina Amanah Cordova secara daring. 


\section{SIMPULAN}

Setelah dilaksanakannya pelatihan, maka dapat disimpulkan bahwa pelatihan ini dapat memberikan solusi mengenai kurangnya pengetahuan peserta didik mengenai bagaimana berkomunikasi dengan konsumen. Sesuai dengan hasil survey yang telah diolah, dapat diketahui bahwa para peserta didik menjadi lebih paham mengenai komunikasi pemasaran, tujuan melakukan komunikasi dengan konsumen, alat-alat komunikasi pemasaran apa saja yang dapat digunakan dan akhirnya peserta dapat memilih alat yang paling sesuai dengan produk dan jasa mereka

\section{UCAPAN TERIMA KASIH}

Penulis mengucapkan terima kasih kepada Fakultas Ekonomi dan Bisnis yang telah menyediakan dana, kemudian kepada DRPMF-FEB yang telah sangat membantu dan mendukung terlaksananya kegiatan Pengabdian Kepada Masyarakat di Sekolah Kewirausahaan Bina Amanah Cordova.

\section{REFERENSI}

Amini, N. A., Rakasiwi, A. G., \& others. (2018). PENGEMBANGAN MODEL PENYULUHAN KESEHATAN PADA KELUARGA UNTUK MENURUNKAN ANGKA KEJADIAN KEKERASAN PADA ANAK DI KABUPATEN BOGOR. PKM- $P, 2(1)$.

ARIANTO, B. (2020). Dampak Pandemi COVID-19 terhadap Perekonomian Dunia. In JURNAL EKONOMI PERJUANGAN (Vol. 2).

Awali, H. (2020). Urgensi Pemanfaatan E-Marketing Pada Keberlangsungan Umkm Di Kota Pekalongan Di Tengah Dampak Covid-19. BALANCA: Jurnal Ekonomi Dan Bisnis Islam, 2(1), 1-14.

Haryadi, R. N., Anda Rojali, Khumidin, \& M. Fauzan. (2021). Sosialisasi Penggunaan Online Shop berbasis Website di UMKM Cimanggis. Jurnal Pengabdian Bina Mandiri, 1(1), 10-16. https://doi.org/10.51805/jpmm.v1i1.3

Hidayanto, A. N., Ovirza, M., Anggia, P., Budi, N. F. A., \& Phusavat, K. (2017). The roles of electronic word of mouth and information searching in the promotion of a new e-commerce strategy: A case of online group buying in Indonesia. Journal of Theoretical and Applied Electronic Commerce Research, 12(3), 69-85.

Human, G., Hirschfelder, B., \& Nel, J. (2018). The effect of content marketing on sponsorship favorability. International Journal of Emerging Markets.

Indayani, S., \& Hartono, B. (2020). Analisis Pengangguran Dan Pertumbuhan Ekonomi Sebagai Akibat Pandemi Covid-19. Jurnal Perspektif, 18(2), 201-208.

Jiang, J., \& Wei, R. (2012). Influences of culture and market convergence on the international advertising strategies of multinational corporations in North America, Europe and Asia. International Marketing Review.

Pratomo, L. A., \& Magetsari, O. N. N. (2018). Online Brand Experience: Drivers and Consequences. JDM (Jurnal Dinamika Manajemen), 9(2), 218-227.

Kotler, P., \& Keller, K. (2011). Marketing management 14th edition. Prentice Hall.

Liu, S. S., \& Comer, L. B. (2007). Salespeople as information gatherers: Associated success factors. Industrial Marketing Management, 36(5), 565-574.

Nasution, D. A. D., Erlina, E., \& Muda, I. (2020). Dampak pandemi Covid-19 terhadap 
perekonomian Indonesia. Jurnal Benefita, 5(2), 212-224.

Yuswohady, Fatahillah, F., Rachmaniar, A., \& Hanifah, I. (2020). Consumer Behavior New Normal After COVID-19:go.id/botol-plastik-bisa-menjadi-sumber-bencana-lingkungan 